\title{
Clinical Efficacy and Therapeutic Alliance in a Time-Limited Group Therapy for Young Adults
}

\author{
Vittorio Lenzo $^{1 \rrbracket}$, Maria Teresa Gargano ${ }^{2}$, Massimo Mucciardi ${ }^{3}$, \\ Girolamo Lo Verso ${ }^{4}$, \& Maria C. Quattropani ${ }^{1}$
}

\begin{abstract}
This study evaluated the clinical efficacy of a time limited psychodynamic therapy for a group of young adult patients in terms of outcome and process. The results register a favourable outcome concerning not only the gravity of patients' initial symptoms but also the structural personality changes and attachment style. In an exploratory perspective this study investigated the connection between the outcome of the tre-atment and therapeutic alliance measured by CALPAS-G in three different time intervals of therapy. A correlational analysis highlighted a strong connection between the Patient Commitment scale assessed at the beginning and the final outcome of the therapy. Working Strategy Consensus and Group Understanding and Involvement assessed in the middle of the therapy course, show significant correlations with the final outcome of therapy.
\end{abstract}

Keywords: group psychotherapy, process-outcome research, attachment; therapeutic alliance; personality disorders

In the last ten years more data on the efficacy and economical use of group psychotherapies has contributed to promoting their diffusion in public services and in clinical practice. However, literature has showed some critical issues among a limited number of research studies in clinical outpatient contexts (Burlingame, Fuhriman, \& Mosier, 2003). There are few studies on analytic and psychodynamic long-term therapies (Tschuschke, Anbeh, \& Kiencke, 2007) whereas there are many studies concerning cognitive behavioral therapies (Burlingame, MacKenzie, \&

\footnotetext{
${ }^{1}$ Department of Humanities and Social Sciences, Psychology Division, University of Messina

2 Department of Human Sciences, LUMSA University, Rome

${ }^{3}$ Department of Economics, Business, Environmental Sciences and Quantitative Methods, Division of Mathematics and Statistics, University of Messina

${ }^{4}$ Department of Psychology, University of Palermo

$\bowtie$ Correspondence concerning this article should be addressed to Vittorio Lenzo, Department of Humanities and Social Sciences, Psychology Division, University of Messina, Via A. Bivona, 1-98122 Messina. E-mail: vittorio.lenzo@unime.it
}

Strauss, 2004). In regard to the Italian scene, research into groups has mainly developed in the theoreticalclinical field rather than in the empirical one (Gullo \& Lo Verso, 2008). Moreover, if we consider the therapeutic process and its connection with the outcome we find other issues. To this end Lorentzen (2006) states that empirical research on long term psychodynamic therapy has analyzed outcome and process variables separately.

Even though the theoretical-clinical literature underlines the contribution of group therapeutic factors (Yalom \& Leszcz, 2009) to the effects of therapy, which include group cohesion and therapeutic alliance, there are some difficulties in an empirical environment starting with the operationalization of the constructs. In the process-outcome research of group therapies many studies consider group cohesion as the variable which mediates the presence of other factors with a direct impact on outcome (Colijn, Hoencamp, Snijders, Van der Spek, \& Duivenvoorde, 1991; Crouch, Bloch, \& Wanlass, 1994; Kipnes, Piper, \& Joyce, 2002; Taube-Schiff, Suvak, Antony, Bieling, \& McCabe, 2007). However, there are as many studies in 
literature as there are definitions of the construct. Therefore, the state of affairs also has repercussions in the empirical field; in fact, it is difficult to compare data derived from different research groups. Recently different definitions of group cohesion have been proposed (Burlingame, McClendon, \& Alonso, 2011) ${ }^{1}$.

In clinical practice the constructs' points of contact and overlap, assessed separately by empirical research, make the interweaving of theory, clinical practice and empirical research even more complex. For this reason when reference is made to group cohesion, therapeutic alliance has to be considered even if the two constructs arose from different fields. In fact, Joyce and colleagues (2007) report that, according to some authors, the cohesion construct used in a group therapy environment, is similar to a therapeutic alliance construct used in individual therapy. The correlation between cohesion and alliance has long been indicated in the empirical field (Budman, Soldz, Demby, Feldstein, Springer, \& Davis, 1989). On the other hand, Marziali and colleagues (1997) demonstrated that alliance in group therapy is significantly related to outcome more than cohesion.

Taking the theoretical debates into account, some essential questions for empirical group research are still controversial. The predictive validity of therapeutic alliance on therapy outcome is one of these questions; currently, while in individual therapies it is fully accepted (Horvath \& Bedi, 2002; Martin, Garske, \& Davis, 2000), it still needs to be clarified in a group therapy environment ${ }^{2}$.

In the last few years, many researchers have shown that change in psychotherapy is not always gradual and linear (Hayes, Laurenceau, Feldman, Strauss, \& Cardaciotto, 2007). Recent studies have also focused on the role of therapeutic alliance as a non static process of psychotherapy (Horvath, 2011; Rocco, Gennaro, De Bei, Zanelli, \& Condino, 2013; Stiles, Glick, Osatuke, Hardy, Shapiro et al., 2004). Evidence from several studies in this field of research has revealed the therapeutic alliance trend in many good outcome psychotherapies and a low value of therapeutic alliance in the middle part of the psychotherapy (e.g., Stiles et al., 2004). However, few studies have explored the trend in psychodynamic group therapies (Giannone, Gullo, Ferraro, Barone, \& Gargano, 2010).

\footnotetext{
${ }^{1}$ For example, the definitions provided first by Piper and colleagues (1983) and later by Budman's unit (1987) led to the fulfillment of two different cohesion assessment instruments. In particular, Piper's unit proposed the Group/ Member/Leader Cohesion Scale (GMLCS), a self-report instrument that evaluates the cohesion relating to each single member of the group. Instead, Budman's unit created the Group Cohesion Scale (GSC) that estimates the group cohesion on the whole, through an observer that works on the transcriptions of group therapy sessions.

${ }^{2}$ For a thorough examination of this subject we refer to other works (e.g., Burlingame, Fuhriman, \& Johnson, 2002; Lingiardi, 2002; Lo Coco, Prestano, Lo Verso; 2008).
}

To date, research into the relationship between the therapeutic factors of group psychotherapies and their outcome has produced contradictory results. In actual fact, the reason could be found in researchers' attempts to isolate aspects that are closely related in the therapeutic process (Gargano, Lenzo, Giannone, \& Lo Verso, 2009).

However, over the years research has been trying to deal with the connection between therapeutic alliance and outcome in group psychotherapy in a more complex way. The studies that have worked on alliance from different points of view belong to this branch of research. Piper, Ogrodniczuk, Lamarche, Hilscher and Joyce (2005) pointed out that, at the beginning of short term group therapy, the patient-rated alliance was related to outcome. Instead, the therapist-rated alliance did not have any significant connection with therapy outcome. Moreover, in a short term group therapy with interpersonal orientation, alliance with the therapist seems to be mainly linked to outcome rather than to cohesion (Joyce, Piper, \& Ogrodniczuk, 2007). Other studies have affirmed that a patient's initial alliance with the therapist is related to the group therapy outcome (Taft, Murphy, King, Musser, \& DeDeyn, 2003; Lorentzen, Sexton, \& Hoglend, 2004). Therefore, this kind of alliance is the strongest predictor and it does not seem to be dependent on the length of group therapy (Bakali, Wilberg, Hagtvet, \& Lorentzen, 2010).

A study conducted by Crowe and Grenyer (2008) concerning a 16-session psychodynamic therapy for patients with major depressive disorders produced different results. In fact, this research showed that the group conflict level and the group members' ability to work actively were related to outcome while the alliance with the therapist was not. Lindgren, Barber and Sandhal (2008) found partially different results with depressed patients attending psychodynamic group therapy. The study confirms that medium alliance levels felt toward the group as a whole, predict the outcome (anxiety and general symptoms level but not depression) while initial alliance levels do not.

On the whole the results obtained through empirical research are often difficult to compare with various parameters $^{3}$ (Di Maria \& Lo Verso, 2002). Horvath (2011) states that one possible reason could be that the vision of therapeutic alliance as a common factor has not provoked a thorough theoretical debate, but just the creation of numerous evaluation instruments (Horvath, 2011). Even very recently in the literature, there has been the proposal of a new definition of alliance and more evaluation instruments (Dorana, Safrana, Waizmannb, Bolgera, \& Muran, 2012; Owen,

\footnotetext{
${ }^{3}$ Aspects that must be taken into account: the group type (e.g. homogeneous in pathology), the therapist's theoretic orientation (e.g., psychodynamic), the treatment duration (e.g.. short term therapy) and the instruments used (e.g., selfreport instruments).
} 
Reese, Quirk, \& Rodolfa, 2013).

Other studies followed a different line of action, introducing the evaluation of other variables, including attachment style, which act as mediators in group cohesion, therapeutic alliance and the outcome of the psychotherapy. In this light, attachment theory is considered a suitable framework to study therapeutic alliance both in individuals (Daniel, 2006) and in group psychotherapy (Flores, 2010; Smith, Msefti, \& Golding, 2010). In addition, some authors have stated that the emotional bonds started in the group could be considered attachment bonds and the group itself can be a safe base for the patients (Mikulincer, \& Shaver, 2007). However, in the empirical field, studies mainly regard individual therapy (Goldman \& Anderson, 2007; Kivlighan, \& Patton, 1998; Reys, \& Grenyer, 2004; Sauer, Lopez, \& Gormley, 2003; Satterfield, \& Lyddon, 1998).

Generally, studies from different theoretical orientations dealing with patients having various psychopathological diagnoses, agree on relating group psychotherapy to a change in patients' attachment style (Keating, Tasca, Gick, Ritchie, Balfour, \& Bissada, 2013, Kinley, \& Reyno, 2013; Maxwell, Tasca, Ritchie, Balfour, \& Bissada, 2013; Tasca, Balfour, Ritchie, \& Bissada, 2007; Tasca, Ritchie, Demidenko, Balfour, Krysanski et al., 2012). With regard to studies dealing with the relationship between attachment and group therapy outcome, a weak plus sign correlation has been found between patient's secure attachment style and the outcome of the therapy itself (Meredith, Strong, \& Feeney, 2007; Meyer, Pilkonis, Proietti, Heape, \& Egan, 2001; Mosheim, Zachhuber, Scharf, Hofmann, Kemmler et al., 2000; Strauss, Lobo-Drost, \& Pilkonis, 1999). However, other studies have found advantages for avoidant (Fonagy, Leigh, Steele, Steele, Kennedy et al., 1996), ambivalent (Sachse \& Strauss, 2002) and insecure style (Joyce, Ogrodniczuk, Piper, \& Sheptycki, 2010). Other authors have not found any correlation between attachment styles and outcome (Cryanowski, Bookwala, Feske, Houck, Pilkonis et al., 2002).

By contrast, a smaller number of studies looked into the relationship between attachment style and some variables of the group therapeutic process. In this branch of research Smith, Murphy and Coats (1999) found that patients with the highest scores in anxious or avoidant attachment showed a lower involvement in group activity, a worse group evaluation and a lower perception of group support. Rom and Mikulincer (2003) showed that patients with a secure attachment style tended to express a better attitude towards the group and a positive memory of interaction and group function. Chen and Mallinckrodt (2002; Mallinckrodt \& Chen, 2004) demonstrated that patients with avoidant attachment style judged the other members to be less friendly. On the other hand, Shechtman and Dvir (2006) registered that patients with a secure attachment obtain higher scores in self-disclosure measures and productivity, showing a responsive attitude towards the group.

With regard to the relationship between attachment style and perceived alliance towards the group, the study by Lindgren and colleagues (2008) found a link between avoidant attachment style and lower levels of initial alliance. Another research study conducted by Tasca and colleagues (2007) found that in psychodynamic groups centered on interpersonal relationships and addressed to patients with a binge eating disorder, a higher anxious attachment and a lower avoidant attachment are related to the growth of group alliance perceived during the group psychotherapy. Tasca and colleagues again, in 2004, revealed that in the same groups, during the treatment, the individual outcomes changed according to anxious and avoidant attachment levels.

Moreover, the results of a wide multicenter study regarding psychodynamic group therapy have recently been published (Kirchmann, Mestel, SchreiberWillnow, Mattke, Seidler et al., 2009). Designed to evaluate the relation among attachment style, personal style, symptoms and some group therapeutic factors, the research involved 289 patients most of whom had a diagnosis of personality disorder. According to the results obtained, the relation between attachment and outcome seems to be mediated by some therapeutic process variables. In fact, patients with a different attachment style seem to have a marked tendency to benefit from a specific therapeutic factor. Nevertheless, as the therapies considered lasted for about 10 weeks, it is difficult to explore the impact of these variables over a longer time span.

Pursuant to the results of this research, personality features seem to have more weight in initial alliance development than the level of symptoms. However, many questions about group therapy for personality disorders are still unresolved, starting with the choice of setting (Gullestad, Wilberg, Kungsøyr, Johansen, Urnes, \& Karterud, 2012).

In view of the considerations expressed so far, this study will present the results of a two- year pilot research which evaluated the efficacy of a long term psychodynamic group therapy for young adults, carried out in a public mental health service. The efficacy was measured by instruments that evaluate general symptomatology, personality structure and attachment style. At the same time the study analyzed therapeutic alliance development with the passing of time as well as its relation to outcome. More specifically, this study had three primary aims.

The first one was to explore the clinical efficacy of a time-limited psychodynamic group therapy for young adults. We hypothesized that favorable outcome regards both the patient's symptoms and structural changes like their personality and attachment style.

The second aim was to explore the relation between therapeutic alliance and outcome of the group therapy. Specifically, we hypothesized that different 
aspects of therapeutic alliance show a specific relation with illness severity in the initial, middle and final phase of the psychotherapy.

Finally, the third aim was to explore the trend of therapeutic alliance over the course of the treatment. We hypothesized the presence of a lower level of therapeutic alliance in the middle phase of therapy than in the initial and the final phases as a result of destabilization before structural changes in personality and attachment style of patients.

\section{Methods $^{4}$}

\section{Participants and Time-limited Group Device}

The research involved 7 patients ( 4 men; 3 women) who were participating in a time-limited psychodynamic group therapy. The patients were young adults between the ages of 18 and 24, with heterogeneous diagnoses 5 . The patients' personality structure, their attachment style and pre-treatment symptoms will be examined in the session concerning outcomes. The treatment took place in the public mental health service in Palermo over two years with weekly 90- minute sessions. The group was coconducted by two group-analytic therapists (Lo Verso \& Di Blasi, 2011). In order to be included in the group, all the patients did a previous six-month individual psychodynamic psychotherapy. None of them had done a previous group psychotherapy. The criteria for inclusion in the group concerned the development phase. Indeed, the patients belonged to the same development phase, so there was homogeneity and a sense of belonging to the main subjects' life stories: This was an important factor for the therapeutic work, considering the time and space limits. The patients had similar relational difficulties. They were going through a specific phase of life during which it is difficult to make plans. They were having difficulties in the following areas: separating from the family matrix ${ }^{6}$ (Foulkes, 1964; Lo Verso, 1994); forming and maintaining bonds; sexual relationships; being at ease with their body.

\section{Instruments}

The Symptom Checklist 90 Revised (SCL 90-R; Derogatis, 1983) is a self-report inventory consisting

\footnotetext{
${ }^{4}$ Methodological aspects were described according to the recommendations by Burlingame, MacKenzie and Strauss (2004) regarding empirical research into group psychotherapy. ${ }^{5}$ This condition is thought mainly to exemplify the complexity which characterizes "real" clinical practice.

6 "The matrix is the hypothetical web of communication and relationship in a given group. It is the common shared ground which ultimately determines the meaning and significance of all events and upon which all communications and interpretations, verbal and non-verbal rest" (Foulkes, 1964, p. 292).
}

of 90 items related to illnesses that may have been experienced in the last week. It examines 10 symptomatic dimensions (Somatization, Obsession-Compulsion, Depression, Anxiety, etc.), and it allows a global score index to be calculated (GSI). For the regulatory data, a German study was referred to (Schimtz, Hartkamp, Kiuse, Franke, Reister, \& Tress, 2000) which fixed GSI $\leq 0.60$ as the measure of mental sanity while GSI $\leq 1.20$ as the cut-off point distinguishing patients with moderate illness (outpatient) from patients with severe illness (inpatient).

The Outcome Questionnaire 45.2 (OQ-45.2; Lambert, Burlingame, Umphress, Hansen, Vermeersch et al., 1996; Lo Coco, Prestano, Gullo, Di Stefano, \& Lambert, 2006) is a self-assessment inventory consisting of 45 items clustered in three subscales which evaluate three aspects of a patient's life: Pathological Symptoms (PS); Interpersonal Relationship (IR); Social Functioning (SF). In the Italian population, the cut-off point that demarcates the passage from a dysfunctional population to a functional one, is estimated to be 66 (Lo Coco et al., 2006).

The Attachment Styles Questionnaire (ASQ; Feeney, Noller, \& Hanrahan, 1994; Fossati et al., 2003) is a self-report inventory designed to evaluate attachment styles. The 40 items of the questionnaire are scored on a six-point Likert scale which investigates the following dimensions: Confidence (C); Discomfort with closeness (DC); Relationship as secondary (RS); Need for approval (NA); Preoccupation with relationship (PR). Each scale is provided with normative data referred to an Italian non-clinical population sample ${ }^{7}$.

The California Psychotherapy Alliance Scale-Group version (CALPAS-G; Lingiardi, \& Croce, 2002; Marmar, \& Gaston, 1988) is a self-report inventory, created to evaluate therapeutic alliance in a group. The questionnaire evaluates four therapeutic alliance indexes. The indexes (Patient working capacity, PWC; Patient commitment, PC; Working strategy consensus, WSC; Group understanding and involvement, GUI) concern patient's contributions to the therapeutic alliance process.

The Shedler-Westen Assessment Procedure (SWAP200; Westen, Shedler, \& Lingiardi, 2003) is a Q-sort instrument which gives a narrative description of a patient's personality profile using standardized language. The instrument is composed of 200 statements which regard the patient and which the therapist has to organize into 8 piles/categories (in numeric scores from 0 to 7).

The SWAP allows a PD score to be obtained, concerning the diagnosis of personality disorder according to DSM criteria, and a $\mathrm{Q}$ score, relative to personality aspects in a dimensional point of view. Both

\footnotetext{
${ }^{7}$ Confidence: $\mathrm{M}=32.25 \pm 5.74$; Discomfort with closeness: $\mathrm{M}=37.95 \pm 7.12$; Relationships as secondary: $16.71 \pm 5.96$; Need for approval: 20.82 \pm 5.99 ; Preoccupation with relationships: $28.81 \pm 6.08$ (Fossati et al., 2003).
} 
scores are expressed in $\mathrm{T}$ points ${ }^{8}$ and the cut-off point is set at 60 .

\section{Procedures}

The study adopts a single-case naturalistic design focusing on the longitudinal observation of the treatment. With regards to the outcome 6 surveys were carried out at constant intervals, through the SCL$90 \mathrm{R}$, the OQ-45, the ASQ, starting with pre-treatment and continuing until post-treatment. Moreover, in order to verify the presence of contingent structural changes in each patient's personality, the two therapists and the observers 9 did two surveys with the SWAP-200.

Regarding the analysis of the therapeutic process, monthly surveys were carried out at regular intervals. The surveys were done through CALPAS-G, starting with the first session until the end of the last one, then they were divided into 3 phases: initial (phase 1), central (phase 2), final (phase 3). Each phase includes 3 contiguous surveys.

The analysis of outcome results was made through the calculus of the Reliable Change Index (RCI; Del Corno \& Lang, 2006; Jacobson \& Truax, 1991; Wise, 2004) so as to evaluate the presence of possible clinically significant changes in relation to the symptomatic categories evaluated by the SCL-90R and the OQ45. The index was calculated according to the

Jacobson-Truax formula (Jacobson et al., 1991), or by verifying whether at the end of treatment the subject's psychological functioning re-entered the normal population according to the parameters of the instrument control sample.

Despite the limits related to designs, which entail a pre- and post- evaluation (Di Nuovo, 1992), this index enables us to verify whether statistically significant differences between pre- and post- scores associate with relevant changes for the patient.

With regard to SWAP-200 the score which, at the end of treatment falls under the cut-off of $60 \mathrm{~T}$ points in the pathological dimensions and above the cut-off in the dimension that refers to a high functioning level and can be considered as a positive outcome. For the ASQ, each score below the average in reference to the nonclinical sample was considered as a positive outcome (Fossati et al., 2003).

Regarding the trend of alliance, a visual analysis of the four component of CALPAS-G was conducted to examine change level in the three phases of group therapy (Di Nuovo, 2013).

A correlational analysis ${ }^{10}$ (Sperman's rho) between the CALPAS-G scales concerning the initial, central, final phase, and each single detection of outcome in-

\footnotetext{
${ }^{8} \mathrm{~T}$ points have $M=50 ; S D=10$

${ }^{9}$ The results pointed out a good concordance between these three values.
}

struments SCL-90R e OQ-45 was used for the therapeutic process. The data was elaborated with SPSS ( $v$. 18; SPSS Inc. 2010).

\section{Results}

\section{Outcome Results}

With regard to SCL-90-R scores, as Table 1 shows at the beginning of the treatment, four patients' GSI exceed the cut-off point (1.20) which identifies the most serious ones.

Table 1. Change from pre- to post-treatment of SCL-90R and OQ-45

\begin{tabular}{|c|c|c|c|c|c|c|}
\hline & \multicolumn{3}{|c|}{ SCRL-90-R } & \multicolumn{3}{|c|}{ OQ-45 } \\
\hline & च゙્ & ज & $\vec{U}$ & $\begin{array}{r}\text { H } \\
\stackrel{0}{H}\end{array}$ & $\begin{array}{l}\text { 曰 } \\
\dot{H} \\
\dot{H}\end{array}$ & $\underset{\mathscr{U}}{\vec{U}}$ \\
\hline 1 & 1.2 & 1.48 & -4.54 & 77 & 87 & -1.75 \\
\hline 2 & 1.78 & 0.68 & $17.96^{*}$ & 71 & 41 & $5.24^{*}$ \\
\hline 3 & 1.59 & 1.53 & 1.81 & 77 & 83 & -1.05 \\
\hline 4 & 1.26 & 0.78 & $7.80^{*}$ & 94 & 87 & 1.22 \\
\hline 5 & 0.36 & 0 & $5.81^{*}$ & 72 & 12 & $10.49^{*}$ \\
\hline 6 & 0.33 & 0.17 & $2.72^{*}$ & 53 & 25 & $4.89^{*}$ \\
\hline 7 & 0.96 & 0.46 & $9.07^{*}$ & 71 & 49 & $3.84^{*}$ \\
\hline
\end{tabular}

*Reliable Change Index $=1.96$; GSI I = pre-treatment Global Index Score; GSI II = post-treatment Global Index Score.

TOT I = pre-treatment OQ-45 total score; TOT II = post-treatment OQ-45 total score; RCI = Reliable Change Index.

\footnotetext{
${ }^{10}$ It is considered worthwhile to highligh some considerations about the statistic analysis made. Despite the problems in making a correlational analysis with limited numbers (e.g., Di Nuovo, 1992), the results can be considered interesting in an exploratory viewpoint. Studies which focused on groups which were heterogeneous for diagnosis and oriented towards young adults and carried out in a public national health service and lasting more than two years were not found in the literature. Because of the limits of this design and the nonparametric results obtained it was decided to use Spearman's range correlation coefficient (rho). Nevertheless, thorough the analysis of the available theoretical and empiric literature, it was possible to exclude a two-tailed experimental hypothesis since it was expected that the relation between therapeutic alliance and outcome would follow a well-defined direction and not the opposite one. At this point on the strength of the table with rho statistics, about the critical values for different levels of probability, only the coefficients with a level of significance at least $p=.05$ in connection with the number of subjects of this research were considered.
} 
Table 2. Change from pre- to post-treatment of SWAP-200

\begin{tabular}{|c|c|c|c|c|}
\hline & GSI I & GSI II & TOT I & TOT II \\
\hline 1 & $\begin{array}{l}\text { Borderline } \\
57.32\end{array}$ & $\begin{array}{l}\text { High functioning } \\
73.65^{*}\end{array}$ & $\begin{array}{l}\text { High functioning Depression } \\
60.16^{*}\end{array}$ & $\begin{array}{l}\text { High functioning Depression } \\
69.22^{*}\end{array}$ \\
\hline 2 & $\begin{array}{c}\text { Histrionic } \\
61.35^{*}\end{array}$ & $\begin{array}{l}\text { High functioning } \\
64.94^{*}\end{array}$ & $\begin{array}{l}\text { Dependent } \\
70.89^{*}\end{array}$ & $\begin{array}{l}\text { High functioning Depression } \\
665.83^{*}\end{array}$ \\
\hline 3 & $\begin{array}{c}\text { Obsessive } \\
61.89^{*}\end{array}$ & $\begin{array}{l}\text { High functioning } \\
65.07^{*}\end{array}$ & $\begin{array}{l}\text { Avoidant } \\
61.28^{*}\end{array}$ & $\begin{array}{l}\text { High functioning Depression } \\
59.82\end{array}$ \\
\hline 4 & $\begin{array}{c}\text { Histrionic } \\
68.91^{*}\end{array}$ & $\begin{array}{l}\text { High functioning } \\
68.26^{*}\end{array}$ & $\begin{array}{l}\text { Histrionic } \\
75.83^{*}\end{array}$ & $\begin{array}{l}\text { High functioning Depression } \\
666.30^{*}\end{array}$ \\
\hline 5 & $\begin{array}{l}\text { Avoidant } \\
54.66\end{array}$ & $\begin{array}{l}\text { High functioning } \\
68.77^{*}\end{array}$ & $\begin{array}{l}\text { Obsessive } \\
57.28\end{array}$ & $\begin{array}{l}\text { High functioning Depression } \\
\qquad 66.12^{*}\end{array}$ \\
\hline 6 & $\begin{array}{l}\text { Histrionic } \\
55.34\end{array}$ & $\begin{array}{l}\text { High functioning } \\
76.80^{*}\end{array}$ & $\begin{array}{c}\text { Narcissistic } \\
69.54^{*}\end{array}$ & $\begin{array}{l}\text { High functioning Depression } \\
699.77^{*}\end{array}$ \\
\hline 7 & $\begin{array}{l}\text { Dependent } \\
58.76\end{array}$ & $\begin{array}{l}\text { High functioning } \\
73.35^{*}\end{array}$ & $\begin{array}{l}\text { Dependent } \\
59.67\end{array}$ & $\begin{array}{l}\text { High functioning Depression } \\
68.71^{*}\end{array}$ \\
\hline
\end{tabular}

Notes: ${ }^{*}>60$ T points; PD-T I = pre-treatment PD-T score; PD-T II = post-treatment PD-T score; Q-T I = pre-treatment Q-T score; $\mathrm{Q}-\mathrm{T} \mathrm{II}=$ post-treatment Q-T score.

However, two patients have a GSI score below the 0.60 pathological threshold. At the end of the therapy, two of the patients with the highest score satisfy both of the standards considered (CS and $\mathrm{RCI})$.

In fact, as patient 2 and patient 4 do not exceed the cut-off point $(G S I=0.83)$, they fall within the statistically normal population (Schimitz et al., 2000). ${ }^{11}$ Their scores also satisfy the other criterion, patient 2 with RCI $=17.96$ and patient 4 with RCI $=7.80$.

After two years, 4 patients, including the abovementioned ones, reached RCI values ranging from 2.72 to 17.49 both for the SCL-90R and for the OQ45, so they satisfy Jacobson and Truax's criterion (1991). At the end of the therapy, patient 7 whose pre-treatment GSI was 0.96 , satisfies both the criteria too $(\mathrm{GSI}=0.46 ; \mathrm{RCI}=9.07)$.

Finally, even though patients 5 and 6 did not have particularly high scores, at the end of the treatment, they improve and register respectively GSI $=0$ and $\mathrm{GSI}=.17$.

As for the OQ-45, all the initial scores are under the cut-off identified for this instrument $(C S=95.53)$ even if all the patients, except for patient 6 , present initial scores above the average (66). Among these, 4 of the seven subjects, obtain a RCI $\geq 1.96$ in a

\footnotetext{
${ }^{11}$ According to the German study (Schmitz et al., 2000) samples do not overlap, so in order to calculate RCI (Jacobson et al., 1991) the cut-off point between the two populations, which represents the intersecting point between the two distributions, has to be considered.
}

range of scores from 3.84 and 10.49 .

\section{Changes in Personality Structure}

As Table 2 shows, three patients present high initial PD-T scores that exceed the cut-off, mainly in Histrionic and Obsessive categories. This data suggests there is more than one personality disorder according to DSM-IV (APA, 2000) $)^{12}$. The personality assessment through Q-T scores reveals a higher variability although there is a greater presence of High Level Functioning, Dependent, Histrionic and Depressive traits. If Table 1 is read in conjunction with Table 2 , it can be noted that a high GSI score relates with a personality disorder.

After two years of group therapy none of the patients have PD scores over the cut-off point while they all have high scores in the High functioning category. However, a strong presence of the High functioning category. However, a strong presence of the High functioning Depressive trait, probably due to the high level of con sciousness the patients gained, can be gathered from Q-T scores.

\footnotetext{
${ }^{12}$ It should be specified that the application of SWAP-200 a month after the beginning of the group, for subjects that were in a particular phase of their life, often characterized by sudden changes (solicited by events such as participation in University classes, precarious work, instability in relationships), forces the researcher and the clinician to a cautious reading of data. In order to make a more careful evaluation of both personality characteristics and their eventual transformation, it is necessary to wait for a wider time span.
} 
Table 3. Change from pre- to post-treatment of ASQ

\begin{tabular}{|c|c|c|c|c|c|c|c|c|c|c|}
\hline & \multicolumn{2}{|c|}{ 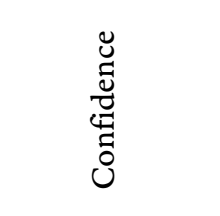 } & \multicolumn{2}{|c|}{ 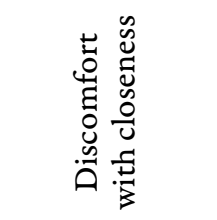 } & \multicolumn{2}{|c|}{ 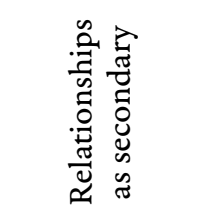 } & \multicolumn{2}{|c|}{ 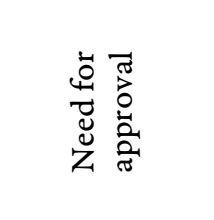 } & \multicolumn{2}{|c|}{ 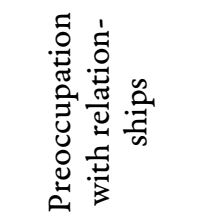 } \\
\hline & I & II & I & II & I & II & I & II & I & II \\
\hline 1 & 28 & 28 & 49 & 42 & 26 & 20 & 25 & 29 & 35 & $24^{*}$ \\
\hline 2 & 26 & $34^{*}$ & 26 & $26^{*}$ & 14 & $13^{*}$ & 33 & 25 & 29 & $28^{*}$ \\
\hline 3 & 27 & 29 & 36 & $36^{*}$ & 18 & 17 & 24 & 28 & 32 & $24^{*}$ \\
\hline 4 & 29 & 24 & 43 & 39 & 20 & 22 & 27 & 29 & 36 & 38 \\
\hline 5 & 25 & $35^{*}$ & 40 & $25^{*}$ & 16 & $11^{*}$ & 29 & $14^{*}$ & 38 & $12^{*}$ \\
\hline 6 & 32 & $42 *$ & 43 & $25 *$ & 16 & $10 *$ & 22 & $15^{*}$ & 32 & $19 *$ \\
\hline 7 & 31 & $33 *$ & 29 & 39 & 19 & 22 & 27 & $17 *$ & 28 & $25^{*}$ \\
\hline
\end{tabular}

Notes: ${ }^{*} \leq \mathrm{M}$ of the nonclinical sample; I = pre-treatment scores; II = post-treatment scores.

\section{Changes in Attachment Style}

If we compare the scores, before and after group therapy, significant changes can be noticed, as Table 3 illustrates ${ }^{13}$. At the end of the treatment, differently from the beginning, four patients obtain Confidence scale scores, in the range of the nonclinical group. This fact indicates they acquired characteristics belonging to a secure attachment style. Moreover, four patients' scores in the scale Discomfort with Closeness, show there is also a decrease in avoidant attachment style characteristics.

At the end of the group therapy we registered a decrease in need for approval and confirmation as the Need for Approval scale shows.

Before the group therapy, six patients out of seven placed themselves in the clinic group relating to the Preoccupation with Relationships scale and in fact they had an anxious and dependent approach to relationships. The group therapy seems to have produced the most important results precisely in these aspects in which the participants obtained the greatest number of improvements. By comparing the results concerning Relationships as a Secondary scale, significant changes were not registered.

$s$ trusting and diligent attitude contributes to a favourable outcome in long term psychotherapy.

\footnotetext{
${ }^{13}$ It must be remembered that regarding the diatribe between categorical and dimensional approaches, the ASQ adopts a dimensional approach in conceptualization of attachment styles.
}

\section{Process Results of Therapeutic Alliance and Outcome}

Initial phase. In Table 4 it can be noticed that, during the first hase, the PC scale of CALPAS-G, Patient Commitment, is significantly associated to the last SCL-90R detection $(-.714 ; p \leq .05)$ and OQ.45 (- .714; $\mathrm{p} \leq .05$ ). It seems plausible to form the hypothesis that the patient's trusting and diligent attitude contributes

Table 4. Correlations between initial phase alliance and pre/post-treatment symptomatology

\begin{tabular}{|c|c|c|c|c|}
\hline & \multicolumn{4}{|c|}{ Scales CALPAS-G } \\
\hline & 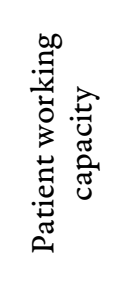 & 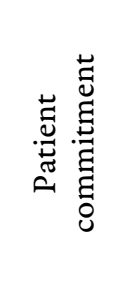 & 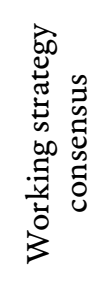 & 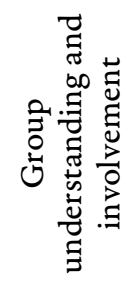 \\
\hline GSI I & -0.381 & -0.285 & 0.360 & 0.018 \\
\hline OQ.45 I & 0.305 & -0.327 & -0.192 & -0.605 \\
\hline GSI II & -0.218 & $-.714^{*}$ & -0.162 & -0.504 \\
\hline OQ.45 II & -0.072 & $-.714^{*}$ & -0.252 & -0.666 \\
\hline
\end{tabular}

Notes: ${ }^{*} p<.05$; $^{* *} p<.01$; GSI I $=$ GSI SCL-90R pretreatment; OQ.45 I = total OQ.45 pre- treatment; GSI II = GSI SCL-90R post-treatment; OQ.45 II = total OQ.45 posttreatment. 
Table 5. Correlations between initial phase alliance and pre/post-treatment symptomatology

\begin{tabular}{|c|c|c|c|c|}
\hline & \multicolumn{4}{|c|}{ Scales CALPAS-G } \\
\hline & 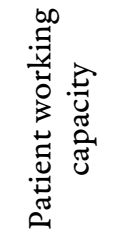 & 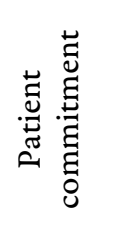 & 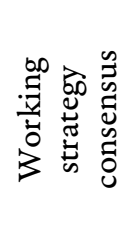 & 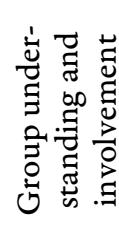 \\
\hline GSI I & -0.306 & 0.037 & 0.018 & -0.126 \\
\hline OQ.45 I & 0.495 & -0.481 & -0.486 & -0.666 \\
\hline GSI II & 0.126 & -0.566 & -0.660 & $-.826^{*}$ \\
\hline OQ.45 II & 0.378 & -0.555 & $-.775^{*}$ & $-.775^{*}$ \\
\hline
\end{tabular}

Notes: ${ }^{*} \mathrm{p}<.05 ;{ }^{* *} \mathrm{p}<.01$; GSI I $=$ GSI SCL-90R pretreatment; OQ.45 I = total OQ.45 pre- treatment; GSI II = GSI SCL-90R post- treatment; OQ.45 II = total OQ.45 posttreatment.

to a favourable outcome in long term psychotherapy.

The absence of a significant correlation between WSC scale (Working strategy consensus) and the outcome standards shows that probably, in this case, the therapist's agreement on the treatment strategies and aims with patient represented an aim of the therapy rather than a point of departure.

At the same time, the absence of significant correlations with PWC scale, that is, Patient's working capacity, could denote that a patient's capacity to reveal the deep contents of themselves, their ability to use the therapist's interpretations in an active way and the possibility of exploring their own contribution to their personal problems are competences that the patients will acquire during the therapeutic process.

Central phase. Table 5 shows that the CALAPS-G WSC scale (Working strategy consensus), registers a significant relation with the result assessed through OQ-45 (-.775; $\mathrm{p} \leq .05)$. Therefore, in this long term therapy, Working strategy consensus could become relevant soon after the initial phase.

At the same time, the absence of significant correlations with the Patient's working capacity scale, could denote that patients' capacity to reveal the deep contents of themselves, their ability to use the therapist's interpretations in an active way and the possibility of exploring their own contribution to their personal problems are competences that the patient will acquire during the therapeutic process.

Moreover Table 5 reveals that, in the central phase of the therapy, the GUI scale, Group Understanding and Involvement, presents negative sign correlations with the outcome, as evaluated through SCL-90R $(-.826 ; p \leq .05)$ and OQ.45 (-.775; $p \leq .05)$.

It seems that, in this phase of the therapy, the non judicial acceptance of the patient, tact and timing to- wards the members and their pain and not-abusing the group to go along with personal needs, assume a strategic role in the therapy outcome.

Final phase. A negative relation was registered between the PC scale, Patient's Commitment, and the survey carried out through OQ-45 (-.679; $p \leq .05)$, at the end of treatment.

Therefore, in the last period of the therapy, the group members' emotional and cognitive commitment seems to be inversely linked to their symptomtic suffering ${ }^{14}$.

A very strong negative correlation was observed among WSC scale, Working strategy consensus, and the outcome of the survey with SCL-90R $(-.750 ; p \leq$ $.05)$ and OQ.45 $(-.893 ; p \leq .05)$ at the end of the therapy too. Also in this case in the last phase, the level of agreement between patients and therapist on the way therapy should proceed seems to be strictly linked to their symptomatic suffering.

Finally we found a very strong negative correlation between the Group understanding and involvement scale and the outcome evaluated through OQ.45 ($.901 ; p \leq .01)$. Therefore, at least in the phase that precedes the end of therapy, patients' involvement towards the group seems to be adversely related to their pain.

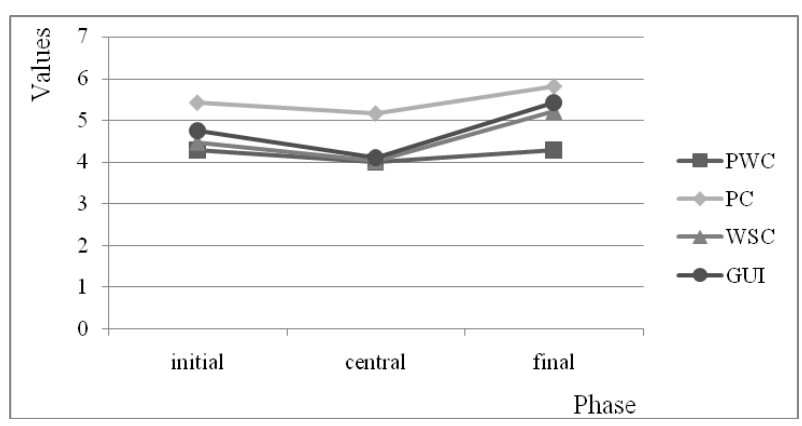

Figure 1. Trend of the therapeutic alliance over time.

\section{Trend of the therapeutic alliance}

As shown in Figure 1, in the middle phase the levels of therapeutic alliance are lower than in the initial and final phase. Specifically, the group understanding and involvement scale showed a lower intensity in the middle part of the group psychotherapy. The other scale of CALPAS-G showed similar trends but with a smaller degree of intensity. Results revealed that therapeutic alliance moved through a high-low-high pattern over the treatment. Moreover, the patient's trust-

\footnotetext{
${ }^{14}$ It must be remembered that OQ-45 compared to SCL$90 \mathrm{R}$ does not evaluate only the pathological symptoms, but also a patient's aspects of life, such as interpersonal relationships and social role functioning.
} 
Table 6. Correlations between final phase alliance and pre/post-treatment symptomatology

\begin{tabular}{|c|c|c|c|c|}
\hline & \multicolumn{4}{|c|}{ Scales CALPAS-G } \\
\hline & 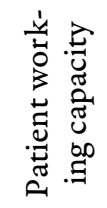 & 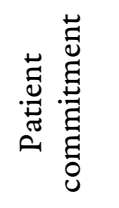 & 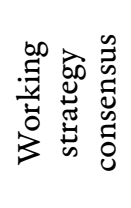 & 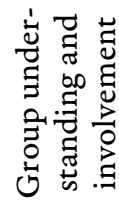 \\
\hline GSI I & $-.775^{*}$ & 0.035 & -0.285 & -0.126 \\
\hline OQ.45 I & -0.137 & -0.381 & -0.436 & -0.467 \\
\hline GSI II & -0.396 & -0.571 & $-.750^{*}$ & -0.630 \\
\hline OQ.45 II & 0.054 & $-.679 *$ & $-.893^{* *}$ & $-.901^{* *}$ \\
\hline
\end{tabular}

Notes: ${ }^{*} \mathrm{p}<.05 ;{ }^{* *} \mathrm{p}<.01$; GSI I $=$ GSI SCL-90R pretreatment; OQ.45 I = total OQ.45 pre-treatment; GSI II = GSI SCL-90R post-treatment; OQ.45 II = total OQ.45 posttreatment.

ing and diligent attitude were critical aspects in the middle phase of the psychodynamic group therapy.

\section{Discussion}

Research evaluating clinical efficacy in group psychotherapy deals with critical methodological and theoretical issues. An essential feature of group therapy is the impact that other group members have on an individual's outcomes, especially in psychodynamically oriented group therapy.

Starting with these considerations and our results, it can be affirmed that time-limited psychodynamic therapy for young adult patients shows a significant clinical efficacy over a period of two years. The favourable outcome regards both the gravity of patients' initial symptoms and structural changes in their personality and attachment style.

At the end of the treatment, patients of this group therapy showed changes mainly in aspects regarding their interpersonal relationships. In fact, the personality evaluation made through the SWAP-200, shows that all the members of the group have a remarkable increase of scores in the category High Functioning (PD factor). However, depressive aspects emerge too ( $Q$ factor), probably related to a stronger consciousness of their own problematical and/or emotional states, and to the approach of separation from the group.

At the same time, substantial positive changes are registered in the attachment style, as the scores of the four ASQ scales show. As well as the increase in secure attachment style characteristics (Confidence), the results reveal a decrease of avoidant attachment style aspects (Discomfort with closeness) and need for approval and confirmation (Need for approval). How- ever, the group therapy seems to have achieved its main result concerning anxious and dependent aspects of patients' interpersonal relationships (Preoccupation with relationships). If these results are read in conjunction with initial personality evaluations, it can be noted that group therapy is efficacious on various personality disorders.

Another aim of this study was to evaluate the association between the initial and/or middle treatment alliance with treatment outcome as well as to verify the efficacy of the therapy. The correlational analysis showed that only the scale regarding patient's commitment, assessed at the beginning of treatment, is significantly related to the final outcome of the therapy. The other CALPAS-G subscales, such as Working strategy consensus and Group understanding and Involvement evaluated in the middle of the therapy, show significant correlations only with the final outcome of the therapy.

Finally, the therapeutic alliance showed a trend over time that moved through a high-low pattern regarding all the aspects. Specifically, the group understanding and involvement scale showed a lower intensity in the middle part of the group psychotherapy. This type of result could be a "specificity" of the long-term group psychodynamic process. In fact, patients feel less understood by the group as a whole and prone to avoidance. Probably, this is due to the progressive work on the members' differentiation processes.

Despite the limits in the research design adopted, it is hoped that additional studies will try to clarify aspects of therapeutic alliance that mostly relate to the outcome of the group therapy. According to the data obtained, in a long term group-analytical orientated therapy, the initial perceived alliance towards the group is not a factor strongly related to the final outcome. During the development of the dynamic process, it seems that the presence of a strong patient commitment is necessary. However, with the passing of time consensus on the work strategy and the kind of emotional involvement become more important.

It seems plausible to think that therapeutic alliance is an aspect of the therapeutic process which has to be built and consolidated over time. In this perspective, a micro-process level of investigation could be precious in order to evaluate the presence of specific patterns relating to the development and the proceeding of alliance in accordance with the therapeutic device used.

\section{References}

American Psychiatric Association (2000). Diagnostic and statistical manual of mental disorders ( $4 \mathrm{t}^{\mathrm{h}}$ ed., Tex Revision. Washington, DC: Author.

Bakali, J.V., Wilberg, T., Hagtvet, K.A., \& Lorentzen, S. (2010). Sources accounting for alliance and cohesion at three stages in group psychotherapy: variance component analyses. Group Dynamics: Theory, Research, and Practice, 14(4), 368-383.

Budman, S.H., Demby, A., Feldstein, M., Redondo, J., Scherz, B., ... Ellis, J. (1987). Preliminary findings on a new instru- 
ment to measure cohesion in group psychotherapy. International Journal of Group Psychotherapy, 37, 75-94.

Budman, S.H., Soldz, S., Demby, A., Feldstein, M., Springer, T., \& Davis, M.S. (1989). Cohesion, alliance and outcome in group psychotherapy. Psychiatry, 52(3), 339-350.

Burlingame, G.M., Fuhriman, A., \& Mosier, J. (2003). The differential effectiveness of group psychotherapy: A metaanalytic perspective. Group Dynamics: Theory, Research, and Practice, 7(1), 3-12.

Burlingame, G.M., MacKenzie, K.R., \& Strauss, B. (2004). Small group treatment: Evidence for effectiveness and mechanisms of change. In M. Lambert (Ed.), Bergin and Garfield's handbook of psychotherapy and behavior change ( ${ }^{\text {th }}$ ed., pp. 648-696). New York: John Wiley \& Sons.

Burlingame, G.M., McClendon, D.T., \& Alonso, J. (2011). Cohesion in Group Therapy. Psychotherapy, 48(1), 34-42.

Chen, E.C., \& Mallinckrodt, B. (2002). Attachment, group attraction and self-other agreement in interpersonal circumplex problems and perceptions of group members. Group Dynamics, 6, 311-324.

Colijn, S., Hoencamp, E., Snijders, H.J.A., Van der Spek, M.W.A., \& Duivenvoorde, H.J. (1991). A comparison of curative factors in different types of group psychotherapy. International Journal of Group Psychotherapy, 41(3), 365377.

Crouch, E., Bloch, S., \& Wanlass, J. (1994). Therapeutic factors: Interpersonal and intrapersonal mechanisms. In A. Fuhriman \& G. Burlingame (Eds). Handbook of group psychotherapy (pp. 269-315). New York: John Wiley \& Sons.

Crowe, T.P., \& Grenyer B.F.S. (2008). Is therapist alliance or whole group cohesion more influential in group psychotherapy outcomes?. Clinical Psychology and Psychotherapy, $15,239-246$

Cryanowski, J.M., Bookwala, J., Feske, U., Houck, P., Pilkonis, P., Kostelnik, B., \& Frank, E. (2002). Adult attachment profiles, interpersonal difficulties, and response to interpersonal psychotherapy in woman with recurrent ma-jor depression. Journal of Social and Clinical Psychology, 21, 191-217.

Daniel, S.L. (2006). Adult attachment patterns and individual psychotherapy: A review. Clinical Psychology Review, 26(8), 968-984.

Del Corno, F., \& Lang, M. (2006). Empirically supported treatments vs empirically supported relationships. In $\mathrm{N}$ Dazzi, V. Lingiardi \& A. Colli (Eds.), La ricerca in psicoterapia (pp. 49-64) [Research in Psychotherapy]. Milano: Raffaello Cortina.

Derogatis, L.R. (1983), SCL-90-R administration, scoring and procedures manual-II. Towson, MD: Clinical Psychometric Researcg.

Di Maria, F., \& Lo Verso, G. (Eds.). (2002). Gruppi. Metodi e strumenti [Groups. Methods and measures]. Milano: Raffaello Cortina.

Dinger, U., \& Schauenburg, H. (2010). Effects of individual cohesion and patient interpersonal style on outcome in psychodynamically oriented inpatient group psychotherapy. Psychotherapy Research, 20, 22-29.

Di Nuovo, S. (1992). La sperimentazione in psicologia applicata. Problemi di metodologia e analisi dei dati [The experiment in applied psychology. Issues of methodology and data analysis]. Milano: Franco Angeli.

Di Nuovo, S. (2013). Per una rilevanza dello studio empirico del cambiamento: quali tecniche di analisi dei dati? [For a relevance of the empirical study of change: what techniques of data analysis?]. Psicologia Sociale, 1, 155-173.

Dorana, J.M., Safran, J.D., Waizmannb, V., Bolgera, K., \& Muran, J.C. (2012). The Alliance Negotiation Scale: Psychometric construction and preliminary reliability and validity analysis. Psychotherapy Research, 22(6), 710-719.
Feeney, J.A., Noller, P., \& Hanrahan, M. (1994). Assessing adult attachment. In M.B. Sperling \& W.H. Berman (Eds.), Attachment in adults: Clinical and developmental perspectives (pp. 128-152). New York: Guilford Press.

Flores, P.J. (2010). Group psychotherapy and neuroplasticity: an attachment theory perspective. International Journal of Group Psychotherapy, 60(4), 546-570.

Fonagy, P., Leigh, T., Steele, M., Steele, H., Kennedy, R., Matton, G., ... Gerber, A. (1996). The relation of attachment status, psychiatric classification and response to psychotherapy. Journal of Consulting and Clinical Psychology, 64(1), 22-31.

Fossati, A., Feeney, J.A., Donati, D., Donini, M., Novella, L., Bagnato, M., ... Maffei, C. (2003). On the Dimensionality of the Attachment Style Questionnaire in Italian Clinical and Nonclinical Participants. Journal of Social and Personal Relationships, 20(1), 55-79.

Foulkes, S.H. (1964). Therapeutic group analysis. London: George Allen \& Unwin.

Gargano, M.T., Lenzo, V., Giannone, F., \& Lo Verso G. (2009). Ripensare l'alleanza terapeutica attraverso lo studio del processo terapeutico nella cura del panico. Due terapie ad orientamento psicodinamico [Alliance and therapeutic process in the psychodynamic therapy of panic disorder]. Rivista di Psicologia clinica, 2, 192-219.

Gaston, L. (1991). Reliability and criterion-related validity of the California Psychotherapy Alliance Scales-Patient Version. Psychological Assessment: A Journal of Consulting and Clinical Psychology, 3, 68-74.

Gaston, L., \& Marmar, C.R. (1994). The California Psychotherapy Alliance Scales. In A.O. Horvath \& L.S. Greenberg (Eds.), The working alliance: Theory, research and practice (pp. 85-108). New York: John Wiley \& Sons.

Giannone, F., Gullo, S., Ferraro, A.M., Barone, R., \& Gargano, M.T. (2010, October). Variazioni nel gruppo. Esiti e processo in un gruppo a lungo termine di pazienti gravi [Outcome and therapeutic process in a long-term group for patients with severe disorder]. Paper presented at the National Conference of Society for Psychotherapy Research-Italy, Perugia, Italy.

Goldman, G.A., \& Anderson, T. (2007). Quality of object relations and security of attachment as predictors of early therapeutic alliance. Journal of Counseling Psychology, 54, 111-117.

Gullestad, F.S., Wilberg, T., Kungsøyr, O., Johansen, M.S., Urnes, Ø., \& Karterud, S. (2012). Is treatment in a day hospital step-down program superior to outpatient individual psychotherapy for patients with personality disorders? 36 month follow-up of a randomized clinical trial comparing different treatment modalities. Psychotherapy Research, 22(4), 426-441.

Gullo, S., \& Lo Verso,G. (2008). La ricerca in psicoterapia di gruppo in Italia [Handbook of Group Therapy Research]. In G. Lo Coco, C. Prestano \& G. Lo Verso (Eds.), L'efficacia clinica delle psicoterapie di gruppo (pp. 117136) [Clinical efficacy of Group Psychotherapy]. Milano: Raffaello Cortina.

Hayes, A.M., Laurenceau, J.P., Feldman, G., Strauss, J.L., \& Cardaciotto, L. (2007). Change is not always linear: The study of nonlinear and discontinuous patterns of change in psychotherapy. Clinical Psychology Review, 27, 715-723.

Horvath, A.O. (2011). Alliance in common factor land: A view through the research lens. Research in Psychotherapy, 14(1), 121-135.

Horvath, A.O., \& Bedi, R.P. (2002). The alliance. In J. Norcross (Ed.), Psychotherapy relations that work. Oxford: Oxford University Press.

Jacobson, N.S., \& Truax, P. (1991). Clinical significance: A statistical approach to defining meaningful change in 
psychotherapy research. Journal of Consulting and Clinical Psychology, 59, 12-19.

Joyce, A.S., Ogrodniczuk, J.S., Piper, W.E., \& Sheptycki, A.R. (2010). Interpersonal predictors of outcome following short-term group therapy for complicated grief: a replication. Clinical Psychology and Psychotherapy, 17(2), 122-135.

Joyce, A.S., Piper, W.E., \& Ogrodniczuk, J.S. (2007). Therapeutic alliance and cohesion variables as predictors of outcome in short- term group psychotherapy. International Journal of Group Psychotherapy, 57(3), 269296.

Keating, L., Tasca, G. A., Gick, M., Ritchie, K., Balfour, L., \& Bissada, H. (2013). Change in attachment to the therapy group generalizes to change in individual attachment among women with binge-eating disorder. Psychotherapy, 51(1), 78-87.

Kinley, J.L., Reyno, S.M. (2013). Attachment style changes following intensive short-term group psychotherapy. International Journal of Group Psychotherapy, 63(1), 53-75.

Kipnes, D.R., Piper, W.E., \& Joyce, A.S. (2002). Cohesion and outcome in short-therm psychodynamic groups for complicated grief. International Journal of Group Psychotherapy, 52, 483-509.

Kirchmann, H., Mestel, R., Schreiber-Willnow, K., Mattke, D., Seidler, K., Daudert, E., ... Strauss, B. (2009). Associations among attachment characteristics, patients' assessment of therapeutic factors, and treatment outcome following inpatient psychodynamic group psychotherapy. Psychotherapy Research, 19(2), 234-248.

Kivlighan, D.M., \& Patton, M.J. (1998). Moderating effects of client attachment on the counselor experience-wprking alliance relationship. Journal of Counseling Psychology, 45, 274-278.

Lambert, M.J., Burlingame, G.M., Umphress, V.J., Hansen, N.B., Vermeersch, D.A., Clouse, G., et al. (1996). The reliability and validity of the Outcome Questionnaire. Clinical Psychology and Psychotherapy, 3, 106-116.

Lindgren, A., Barber, J.P., \& Sandhal, C. (2008). Alliance to the group-as-a-whole as a predictor of outcome in psychodynamic group therapy. International Journal of Group Psychotherapy, 58(2), 163-184.

Lingiardi, V. (2002). L'alleanza terapeutica. Teoria, clinica, ricerca [Therapeutic Alliance: Theory, Clinical practice and Research]. Raffaello Cortina: Milano.

Lingiardi, V., \& Croce, D., (2002). The California Psychotherapy Alliance Scale-Group version. In V. Lingiardi (Ed.), L'alleanza terapeutica. Teoria, clinica, ricerca (pp. 101-102) [The Therapeutic Alliance: Theory, Clinical practice and Research]. Milano: Raffaello Cortina.

Lo Coco, G., Prestano, C., Gullo, S., Di Stefano, G., \& Lambert, M.J. (2006). Un primo studio sulla validazione italiana dell'Outcome Questionnaire (OQ-45.2) $\square$ The Italian version of the Outcome Questionnaire $\square$. Ricerca in psicoterapia, 9(1), 7-19.

Lo Coco, G., Prestano, C., \& Lo Verso, G. (Eds.). (2008). L'efficacia clinica delle psicoterapie di gruppo [Clinical efficacy of the Group Psychotherapy]. Milano: Raffaello Cortina.

Lo Verso, G. (1994). Le relazioni soggettuali. Fondazione della psicologia dinamica e clinica [Beyond the Object Relations Theory: A new framework for dynamic and clinical psychology]. Torino: Bollati Boringhieri.

Lo Verso, G., \& Di Blasi, M. (2011). Gruppoanalisi soggettuale [Handbook of Group Analysis]. Milano: Raffaello Cortina.

Lorentzen, S. (2006). Contemporary challenges for research in Group Analysis. Group Analysis, 39(3), 321-340.

Lorentzen, S., Sexton, H.C., \& Hoglend, P. (2004).
Therapeutic alliance, cohesion and outcome in a long-term analytic group. A preliminary study. Nordic Journal of Psychiatry, 58(1), 33-40.

Mallinckrodt, B., \& Chen, E.C. (2004). Attachment and interpersonal impact perceptions of group members. Psychotherapy Research, 14, 210-230.

Marmar, C.R., \& Gaston, L. (1988). Manual for the California Psychotherapy Alliance Scale CALPAS. Unpublished manuscript, Department of Psychiatry, University of California, San Francisco.

Martin, D.J., Garske, J.P., \& Davis, M.K. (2000). Relation of the therapeutic alliance with outcome and other variables: a meta-analytic review. Journal of Consulting and Clinical Psychology, 68(3), 438-450.

Marziali, E., Munroe-Blum, H., \& McCleary, L. (1997). The contribution of group cohesion and group alliance to the outcome of group psychotherapy. International Journal of Group Psychotherapy, 47(4), 475-497.

Maxwell, H., Tasca, G.A., Ritchie, K., Balfour, L., \& Bissada, L. (2013). Change in attachment insecurity is related to improved outcomes 1 year post group therapy in women with binge eating disorder. Psychotherapy, 58(1), 57-65.

Meredith, P.J., Strong, J., \& Feeney, J. (2007). Adult attachment variables predict depression before and after treatment for chronic pain. European Journal of Pain, 11, 164170.

Meyer, B., Pilkonis, P.A., Proietti, J.M., Heape, C.L., \& Egan, M. (2001). Attachment styles, personality disorders, and response to treatment. Journal of Personality Disorders, 15, 371-389.

Mikulincer, M., \& Shaver, P.R. (2007). Attachment, grouprelated process and psychotherapy. International Journal of Group Psychotherapy, 57, 233-245.

Mosheim, R., Zachhuber, U., Scharf, L., Hofmann, A., Kemmler, G., Danzl, C., ... Richter, R. (2000). Bindung und Psychotherapie [Attachment and psychotherapy]. Psychotherapeut, 45, 23-229.

Ogrodniczuk, J.S., \& Piper, W.E. (2003). The effect of group climate on outcome in two forms of short-term group therapy. Group Dynamics: Theory, Research, and Practice, 7(1), 64-76.

Owen, J., Reese, R.J., Quirk, K., \& Rodolfa, E. (2013). Alliance in action: A new measure of clients' perceptions of therapists' alliance activity. Psychotherapy Research, 23(1), 67-77.

Piper, W.E., Marrache, M., Lacroix, R., Richardson, A.M., \& Jones, B.D. (1983). Cohesion as a basic bond in groups. Human Relations, 36, 93-108.

Piper, W.E., Ogrodniczuk, J.S., Lamarche, C., Hilscher, T., Joyce, A.S. (2005). Level of alliance, pattern of alliance, and outcome in short-term group therapy. International Journal of Group Psychotherapy, 55(4), 527-550.

Reys, S., \& Greenyer, B.F.S. (2004). Fearful attachment, working alliance and treatment response for individuals with major depression. Clinical Psychology and Psychotherapy, 11, 414-424.

Rocco, D., Gennaro, A., De Bei, F., Zanelli, D., \& Condino, V. (2013). Development and charatheristics of the therapeutic alliance in a short-term dynamic psychotherapy: a descriptive case study. Research in Psychotherapy: Psychopathology, Process and Outcome, 16(1), 33-41.

Rom, E., \& Mikulincer, M. (2003). Attachment theory and group processes. Journal of Personality and Social Psychology, 84, 1220-1235.

Sachse, J., \& Strauss, B. (2002). Bindungscharakteristika und Behandlungserfolg nach stationärer psychodynamischer Gruppentherapie [Attachment characteristics and psychotherapy outcome following inpatient psychodynamic group treatment]. Psychotherapie, Psychosomatik, Medizinische Psychologie, 52, 134-140. 
Safran, J.D., Muran, J.C., \& Proskurov, B. (2009). Alliance, negotiation and rupture resolution. In R.A. Levy \& J.S. Ablon (Eds.), Handbook of evidence based psychodynamic therapy (pp. 201-225). New York: Human Press.

Sauer, E.M., Lopez, F.G., \& Gormley, B. (2003). Respective contribuitions of therapist and client adult attachment orientations to the development of the early working alliance: A preliminary growth modeling study. Psychotherapy Research, 13, 371-382.

Satterfield, W.A., \& Lyddon, W.J. (1998). Client attachment and the working alliance. Counseling Psychology Quarterly, 11, 497-415.

Schmitz, N, Hartkamp, N, Kiuse, J, Franke, G.H., Reister, G., \& Tress, W. (2000). The Symptom Check-List-90-R (SCL90-R): A German validation study. Quality of Life Research, 9, 185-193.

Shechtman, Z., \& Dvir, V. (2006). Attachment styles as a predictor of behavior on group counseling with preadolescents. Group Dynamics, 10, 29-42.

Smith, A.E.M., Msefti, R.M., \& Golding, L. (2010). Client self rated adult attachment patterns and the therapeutic alliance: A systematic review. Clinical Psychology Review, 30, 326-337.

Smith, E.R., Murphy, J., \& Coats, S. (1999). Attachment to groups: Theory and measurement. Journal of Personality and Social Psychology, 77, 94-110.

Stiles, W.B., Glick, M.J., Osatuke, K., Hardy, E.G., Shapiro, D.A., Agnew-Davies, R., \& Barkham, M. (2004). Patterns of alliance development and the rupture repair hypothesis: are relationship U-shaped or V-shaped? Journal of Counseling Psychology, 51(1), 81-92.

Strauss, B., Lobo-Drost, A., \& Pilkonis, P. A. (1999). Einschätzung von Bindungsstilen bei Erwachsenen [Assessment of adult attachment styles]. Zeitschrift für Klinische Psychologie, Psychiatrie und Psychotherapie, 47, 347-364.

Taft, C. T., Murphy, C. M., King, D. W., Musser, P. H., \& DeDeyn, J. M. (2003). Process and treatment adherence factors in group cognitive-behavioral therapy for partner violent men. Journal of Consulting and Clinical Psychology, $71(4), 812-820$

Tasca, G.A., Balfour, L., Ritchie, K., \& Bissada, H. (2007). Change in attachment anxiety is associated with improved depression among women with binge eating disorder. Psychotherapy: Theory, Research, Practice, Training, 44(4), 423-433.

Tasca, G.A., Ritchie, K., Demidenko, N., Balfour, L., Krysanski, V., \& Weekes, K., ... Bissada, L. (2012). Matching women with binge eating disorder to group treatment based on attachment anxiety: Outcomes and moderating effects. Psychotherapy Research, 1, 1-14.

Tasca, G.A., Taylor, D., Bissada, H., Ritchie, K., \& Balfour, L. (2004). Attachment predicts treatment completion in an eating disorders partial hospital program among women with anorexia nervosa. Journal of Personality Assessment, 83, 201-212.

Taube-Schiff, M., Suvak, M.K., Antony, M.M., Bieling, P.J., \& McCabe, R.E. (2007). Group cohesion in cognitivebehavioral group therapy for social phobia. Behavior Research and Therapy. 45, 687-698.

Tschuschke, V., Anbeh, T., \& Kiencke, P. (2007). Evaluation of long-term analytic outpatient group therapies. Group Analysis. 40, 140-159.

Westen, D., Shedler, J., \& Lingiardi, V. (2003). La valutazione della personalità con la Swap-200 [The assessment of personality with SWAP-200]. Milano: Raffaello Cortina.

Wise E.A. (2004). Methods for analyzing psychotherapy outcomes: A review of clinical significance, reliable change, and recommendations for future directions. Journal of Personality Assessment, 82(1), 50-59.

Yalom, I.D., \& Leszcz, M. (2009). Teoria e pratica della psicoterapia di gruppo [The Theory and Practice of Group Psychotherapy]. Torino: Bollati Boringhieri.

Submitted May 27, 2013

Revision received July 28,2014 Accepted December 26, 2015 